\title{
What Drives Inflation-Output Tradeoff Dynamics in Pakistan? An Assessment of International Linkages and Global Trends
}

\author{
Muhammad Ayyoub* and Julia Wörz ${ }^{* *}$
}

\begin{abstract}
This article illustrates the dynamics of and tradeoff between inflation and output in Pakistan by utilizing data on 18 major trading partners in a cointegration analysis. In doing so, we use key features of the global vector autoregressive approach to construct a model that captures foreign-specific variables related to Pakistan; these are analyzed empirically along with domestic data for the period 1972-2014. Our findings show that, after accounting for the impact of increasing interdependencies, trade spillovers and changing global macroeconomic conditions, a long-run equilibrium relationship exists between domestic inflation and output. The foreign variables have a significant impact on the key domestic variables. In particular, domestic inflation and trade openness, foreign inflation and world oil prices have significant explanatory power for Pakistani output. Policymakers in Pakistan should therefore account for global developments, specifically in trading partner economies.
\end{abstract}

Keywords: cointegration, cross-country spillovers, inflation-output dynamics, oil prices, Pakistan.

JEL classification: E31, E52, O47.

\section{Introduction}

Any policy analysis of the inflation-output tradeoff dynamics in Pakistan requires accounting for increasing interdependencies, trade spillovers, specific sectoral effects and changing macroeconomic conditions at the domestic as well as global level. Similarly, policymakers need to take into account the channels of transmission, such as changes in oil prices. However, the existing literature on the inflation-growth relationship does

\footnotetext{
${ }^{*}$ PhD Program in Economics, offered jointly by the University of Innsbruck and Johannes Kepler University, Linz, Austria.

${ }^{* *}$ Head of the Central, Eastern and Southeastern European Analysis Unit, Foreign Research Division, Osterreichische Nationalbank, Vienna, Austria.

The authors gratefully acknowledge useful comments and suggestions from two anonymous referees. The usual disclaimer applies
} 
not fully control for simultaneity bias and country-specific effects in growth regressions. ${ }^{1}$ It also overlooks global trends and third-country effects, and often neglects the dynamic aspects of this relationship. Furthermore, panel regression studies tend to treat all of the considered economies as independent units of observation, thereby ignoring cross-country spillovers.

Aside from sectoral models, time series analysis also has its shortcomings. Country-specific models such as vector autoregressive (VAR) models generally ignore international linkages, although these are crucial to examining spillover effects between different economies. The practice of combining several VARs into one panel VAR does not include contemporaneous endogenous variables. All this can lead to misleading analysis and conclusions (Dees et al., 2014). Therefore, a greater number of global variables is needed in the analysis to reduce cross-country correlations, identify country-specific idiosyncratic shocks, and a control for typically unobserved global factors such as the diffusion of technological progress.

We aim to test the hypothesis that trade spillovers, increasing interdependencies, changing global macroeconomic conditions and thirdcountry effects matter when examining the inflation-output dynamics of Pakistan. Similarly, we test the hypothesis that channels of transmission, such as changes in oil prices, are significant. More specifically, we focus on two empirical questions: (i) what are the long-run impacts and nature of the relationship between inflation and output in Pakistan when considering international linkages and spillovers? (ii) what are the consequences of 'third-country effects' on the dynamics of the relationship? We argue that this empirical exercise should provide a clearer picture of the relationship in question and that trade spillovers and cross-country linkages should matter significantly when examining Pakistan's economy.

We are concerned with these policy questions based on two broader arguments. First, as with many other important macroeconomic concerns, the stability of the long-run inflation-output relationship has vital implications for achieving monetary policy goals. Despite some wellestablished stylized facts for Pakistan, only a handful of empirical studies consider external linkages such as oil price variations, third-country effects and trade spillovers. Second, during the last decade, almost all domesticlevel studies have either focused on examining the interest rate channel of the monetary policy transmission mechanism or tried to determine feasible

\footnotetext{
${ }^{1}$ Important existing studies are reviewed in Section 2.
} 
threshold levels of the inflation-growth relationship. Some studies have investigated the effects of oil price shocks on the macroeconomy. Therefore, at least for Pakistan and to the best of our knowledge, there is a dire need to empirically examine inflation-output dynamics by bringing external linkages and interdependencies into the picture.

We estimate and evaluate the stability and robustness of inflationoutput dynamics in the presence of weakly exogenous foreign-specific inflation-output variables and global variables. This study contributes significantly to the literature on Pakistan's economy for two reasons: (i) there is a demand for literature dealing primarily with cross-country spillovers; and (ii) even though Pakistan's major trading partners are oil-exporting countries (for example, Saudi Arabia, the UAE, Kuwait and Iran), the literature incorporating oil price changes in the context of inflation-output dynamics is lacking.

We find that, after taking into account the impact of foreign-specific variables, a stable long-run and well-determined inflation-output relationship exists in Pakistan during the period under study (1972-2014). The dynamics of the relationship in question are captured by our Pakistanspecific vector error correction model. The foreign-specific variables have a significant impact on the key domestic variables. Foreign inflation and output and world oil prices are significant determinants of domestic output as well as domestic inflation and openness. As our findings demonstrate a considerable difference from previous works, the implications of these results may also be of great interest to policymakers in Pakistan.

The structure of this article is as follows. Section 2 briefly discusses the previous research conducted in Pakistan on the relationship in question while Section 3 outlines the theoretical considerations needed to empirically test our hypothesis. Our empirical implementation strategy is detailed in Section 4. Section 5 presents the dataset, variables and descriptive statistics. Section 6 discusses the main results and robustness of our findings. Section 7 concludes the article and gives suggestions for further research on this topic.

\section{What Has Been Done So Far in Pakistan?}

While there exist some empirical evidence on the linkages between the 'inflation-output tradeoff' and trade interdependencies at the global level, studies related to Pakistan are scarce. Earlier works on the inflationgrowth nexus in Pakistan conclude that inflation hurts economic growth 
beyond a certain threshold level. ${ }^{2}$ As mentioned above, the existing studies on Pakistan are partially relevant to our hypothesis. In this section, we include only those studies that have employed a partially relevant method, similar model or the same dataset.

We start with a review some of the important studies of the last decade. Based on a four-variable (i.e., rates of GDP growth, inflation, population growth, and total investment) model estimated using causality and sensitivity tests, Mubarik (2005) shows that the Granger causality test defines unidirectional causality from inflation to economic growth but not vice versa. Qayyum (2008) proposes a monetary policy framework and highlights its effectiveness in controlling inflation. He argues that, although the monetary authorities remained successful in keeping a check on inflation, the State Bank of Pakistan (SBP) failed to control the money supply, which resulted in a failure to meet the settled target for inflation.

Saleem (2010) estimates a VAR model using annual data for the period 1970-2009 and helps explain why the SBP should target the interest rate to adjust the output-inflation tradeoff in the economy. This empirical examination considers a model that includes the CPI inflation rate, the call money rate and the output gap, and reveals a negative relationship between GDP growth and inflation during the studied period. These findings provide evidence of the effectiveness of the interest rate channel in stabilizing prices in Pakistan. Saleem suggests that inflation targeting could help maintain the inflation-output relationship.

Based on annual data (1960-2006), Hussain and Malik (2011) examine the inflation-growth nexus by adopting an error correction approach for two key variables. They also find a unidirectional relationship between inflation and economic growth, and provide empirical evidence that 49 percent of the adjustment towards the short-run equilibrium relationship between inflation and growth occurred within the same year.

More recently, Moazam and Kemal (2016) investigate the determinants of inflation in Pakistan and test the hypothesis that inflation is a monetary phenomenon. Building their model on the quantity theory of money, they use money supply, GDP and prices as a function of oil prices. Their study reveals a strong association between money supply and prices, and GDP and prices. A link is also observed between oil prices and commodity prices. The analysis, conducted using the Johansen cointegration

\footnotetext{
${ }^{2}$ Mubarik (2005); Hussain and Malik (2011); Ayyoub and Woerz (2016), among others.
} 
method, provides evidence that relationships exist between the selected variables in the long run. The money supply is found to be the most important determinant of inflation in the long run, whereas changes in oil prices affect prices significantly, but only in the short term. The study also establishes a channel for a long-run relationship, according to which, as the demand for foreign exchange changes, the money supply also changes. Consequently, domestic prices are mitigated by changes in oil prices. On the same grounds, money is found to be responsible for supply-side shocks in the long run. Hence, the pass-through effect of inflation lasts only in the short run.

Our review of the literature on Pakistan shows the significance of our research question and testable hypotheses. Given our approach to this issue, we hold that our findings provide fresh empirical evidence that is relevant to policymaking in Pakistan and in general to other economies in the developing world.

\section{Theoretical Considerations and Empirical Support}

Investigating the relationship and dynamics of inflation-output adjustment in Pakistan requires a mechanism that can account for linkages with trading partners and allows for feedback effects between inflation, output, cross-country interactions and trade spillovers. To the best of our knowledge, the literature does not provide any formal theoretical model that covers all these concerns. It does, however, present separate approaches to inflation and growth, interdependencies and integration of economies and the potential effects on macroeconomic performance, and the impact of oil price changes on macroeconomic aggregates. Based on the existing studies, we propose a mechanism that is identified mainly by inflation-output tradeoff dynamics. This channel links our key variables with global trends, common fluctuations among various economies and trade interdependencies among Pakistan's trading partners. These assumed relationships constitute the framework used to address our research question and test the underlying hypotheses. Our arguments are based on Mankiw et al. (1992), Gylfason (1999) and Cunado and de Gracia (2005).

Here, it is necessary to explain the foundations of the inflationoutput tradeoff and understand how the dynamics of the relationship in question work. ${ }^{3}$ The inflation-output tradeoff relationship is derived from the Philips curve (PC), which was central to macroeconomic policymaking

\footnotetext{
${ }^{3}$ The authors are grateful to an anonymous referee for highlighting this argument.
} 
in the UK and elsewhere for decades. However, as Fuhrer (1995) points out, the main criticism of the PC is that the model is not structural; Lucas (1976) also argues that it is not stable over a longer period. Despite being an empirical relationship, the argument is that, as monetary policy switches between different regimes, there is no theoretical reason that the underlying parameters of the PC will remain unchanged. Even if the behavior of economic agents remained stable between different regimes, the relationship between aggregate variables could easily change if conditions vary in unaccounted-for linkages. Based on these arguments, and given that developments with respect to trading partners and international linkages are considered in policymaking, this study is also an attempt to account for the ideas presented in the Lucas critique.

In the specific context of developing economies, one argument that runs counter to the predictions of the PC is that there exists a negative relationship between inflation and output (see, for instance, Dholakia, 1990; Ghani, 1991; Virmani, 2004). However, when output is measured by the index of industrial production, Mazumder (2011) reports a strong positive relationship between inflation and output. In this respect, our study is an attempt to explain, at least from an empirical point of view, how the PC's predictions work for inflation-output tradeoff dynamics in Pakistan, when international linkages and global trends are taken into account.

Since the existence of an inflation-output tradeoff in the long run is highly questionable, most economists agree that the relationship between the two exists only in the short to medium term (Hartmann \& Roestel, 2013). As far as the adverse impact of inflation is concerned, a popular view is that the effect of inflation on output comes into play when inflation crosses a certain threshold (Lopez-Villavicencio \& Mignon, 2011). The consensus on the transmission mechanism (see, for instance, Khan \& Senhadji, 2001) is that there are many channels through which the inflationoutput tradeoff is established.

There are two fundamental views, both based on substantial empirical literature. One school of economists believes that inflation is a monetary phenomenon while growth is a real phenomenon, and that the former does not therefore affect the latter in the long run. ${ }^{4}$ Supporters of the opposing view argue that price stability is a precondition for a stable growth trend. ${ }^{5}$ In this respect, we move a step ahead and incorporate a greater

\footnotetext{
${ }^{4}$ For instance, Barro and Sala-i-Martin (1995), among others.

${ }^{5}$ For example, widely cited contributions of Barro (1996); Khan and Senhadji (2001).
} 
number of factors to analyze the relationship in question. Mankiw et al. (1992) postulate that international trade can raise the level of output produced by the given inputs. This is made possible through increased efficiency.

However, as Gylfason (1999) points out, if domestic prices increase and there is no instantaneous adjustment of the nominal exchange rate with prices, inflation and the real exchange rate will keep moving in opposite directions and this will, in turn, affect exports and output growth negatively. A higher import-to-GDP ratio and smaller export-to-GDP ratio and inflation work as proxies for inefficiency and affect production in their own right. Therefore, we can conclude that trade openness increases efficiency and, eventually, production and growth. Gylfason also finds that high inflation is connected to low exports and slower growth, and that high inflation tends to be associated with a low export-to-GDP ratio and, in turn, with slow growth.

Cunado and de Gracia (2005) argue that an oil shock, particularly in an international context, may have a different impact on each country depending on variables such as international linkages, sectoral composition, countries' relative position as oil exporters or importers and their different tax structures. According to Blanchard and Riggi (2013), macroeconomists look at changes in oil prices not only as a significant source of fluctuations but also as a global supply shock, which affects many economies at a given point.

Many researchers hold that an increase in oil prices results in higher inflation (see, for instance, Hooker, 2002). Eventually, an increase in oil prices implies an inflationary shock. They propose a transmission approach according to which, this inflationary shock can be supplemented with second-round effects through the price-wage loop. However, some argue that an increase in oil prices exerts only a moderate influence. According to the proposed transmission mechanism, the classic supplyside effect can explain the connection between oil prices and output (Abel \& Bernanke, 2001). Rising oil prices indicate reduced availability or an increase in the cost of an essential production input, which can lead to a potential reduction in output. In turn, an increase in the cost of production leads to changes in productivity, output and growth. Hamilton (2016) concludes that, after a certain period, this impact is weakened. The study also finds that the direct inflationary impact of oil price changes affects mostly developed countries, while fewer effects of lower magnitude are observed in developing economies. 
In light of these connections described above, we can argue that the inflation-output tradeoff in an economy is established through the effects of worldwide trends, cross-country interactions and trade spillovers. This calls for testing the hypothesis that underlies this relationship, by examining this mechanism.

\section{Empirical Implementation Strategy}

There is a growing interest in 'spillovers' in the global vector autoregressive (GVAR) methodology advanced by Pesaran et al. (2004). These cross-country effects can be defined as the disturbances in the reference economy caused by policy actions taken by its trading partners. Recent empirical applications of the GVAR method show that it is effective in dealing with interdependencies, trade spillovers, global effects and specific sectoral effects. ${ }^{6}$ This approach provides a straightforward solution for analyzing the relationship between variables such as inflation and output dynamics across economies.

In the context of the inflation-output tradeoff discussed above, an effective econometric tool is required to deal with factor interdependencies and common swings among Pakistan's trading partners. Since the GVAR method has been used effectively in dealing with international comovements of business cycles (Dees et al., 2007), we have the benefit of using its most crucial feature, the ability to capture foreign-specific variables, to establish a transmission mechanism. As the number of economies increases $(\mathrm{N} \rightarrow \infty)$, foreign variables become weakly exogenous.

By exploiting this feature of the GVAR method, we can link our key domestic variables with weakly exogenous foreign-specific variables. The foreign-specific variables of real GDP and inflation are constructed as weighted averages of the domestic variables for all Pakistan's partner economies. By doing so, we incorporate international linkages with domestic inflation-output variables, and we can evaluate the patterns of co-movement of real output and inflation in a multi-country framework. Another advantage is that this modeling procedure is suitable for all data frequencies.

\subsection{Foreign-Specific Variables}

Based on Pakistan's bilateral trade flows with 18 economies, the foreign-specific variables - which serve as proxies for the impact of foreign

\footnotetext{
${ }^{6}$ For example, Dees et al. (2007), and di Mauro and Smith (2013), among others.
} 
economic developments - are calculated as the weighted averages of their counterpart domestic variables. ${ }^{7}$ These variables are needed not only to match the relative significance of trading partners, but also to allow for interdependencies between Pakistan and its partners. An additional benefit of foreign-specific variables is that they provide an accurate proxy representation of unobserved worldwide factors such as the diffusion of technological progress.

In our empirical setting, Pakistan is a reference economy $i$ and all its partner economies are denoted by $j=1,2, \ldots, N$. Hence, $x_{i t}^{*}=$ $\sum_{j=1}^{N} w_{i j} x_{j t}=W_{i} x_{t}$, where $w_{i j}$ is a set of weights such that $w_{i i}=0$ and $\sum_{j=0}^{N} w_{i j}=1 . W_{i}$ is a country-specific weight matrix or link matrix, and $w_{i j}$ is the trade weight of country $j$ in the trade of Pakistan, $i$. These trade weights can be fixed or time-varying, depending on trade structure or financial linkages. Following Pesaran et al. (2004) and Dees et al. (2007), we use trade weights (see Appendix) based on average trade flows calculated using annual data over three years, 2010-12.

\subsection{Empirical Model (VECMX ${ }^{*}$}

The general VECMX* structure, when including a weakly exogenous $X^{*}$, is written as follows: ${ }^{8}$

$$
\begin{aligned}
x_{i t}= & a_{i 0}+a_{i 1} t+\Phi_{i 1} x_{i, t-1}+\Phi_{i 2} x_{i, t-2}+\Lambda_{i 0} x_{i, t}^{*}+\Lambda_{i 1} x_{i, t-1}^{*}+\Lambda_{i 2} x_{i, t-2}^{*}+ \\
& \mu_{i t}
\end{aligned}
$$

where $t=1,2, \ldots \mathrm{T}$ is the time period, $x_{i t}$ is a $k \times 1$ vector of domestic variables, $x_{i t}^{*}$ is a $k^{*} \times 1$ vector of foreign-specific variables and $\mu_{i t}$ is a correlation-free process. The vectors and matrices are represented by lower and upper-case letters, respectively. The numbers of domestic and foreignspecific variables are represented by $k_{i}$ and $k_{i}^{*}$, respectively.

We can use foreign-specific variables $\left(x_{i t}^{*}\right)$, built from interactions between Pakistan and its partner economies, through two channels: (i) the contemporaneous dependence of domestic variables $\left(x_{i t}\right)$ on foreign-specific variables $\left(x_{i t}^{*}\right)$ and on their lags, and (ii) the dependence of domestic variables $\left(x_{i t}\right)$ on global variables $\left(d_{i t}\right)$. Examples of global variables are

\footnotetext{
${ }^{7}$ As shown in the Appendix, China is Pakistan's most important trading partner, followed by the UAE, Saudi Arabia, USA, Kuwait, Malaysia, India, Germany, Japan, Iran, UK, Singapore, South Korea, Italy, Indonesia, France, Thailand and Turkey.

${ }^{8} X^{*}$ comprises weakly exogenous foreign-specific variables, $x_{i t}^{*}$, and global variables, $d_{i t}$.
} 
energy prices, food prices and oil prices. We consider world oil prices as our global variable.

Let us assume a simple specification $[\operatorname{VAR}(1,1)]$ and write $(1)$ as:

$$
x_{i t}=\Phi_{1} x_{i, t-1}+\Lambda_{i 0} x_{i, t}^{*}+\Lambda_{i 1} x_{i, t-1}^{*}+\mu_{i t}
$$

For simplicity, let us illustrate (2) using a two-variable case (output and inflation) for Pakistan. Here, the Pakistan-specific model in the presence of two foreign-specific variables looks like:

$$
\left[\begin{array}{l}
y_{t} \\
\pi_{t}
\end{array}\right]=\Phi_{1}\left[\begin{array}{l}
y_{t-1} \\
\pi_{t-1}
\end{array}\right]+\Lambda_{i 0}\left[\begin{array}{c}
y_{t}^{*} \\
\pi_{t}^{*}
\end{array}\right]+\Lambda_{i 1}\left[\begin{array}{l}
y_{t-1}^{*} \\
\pi_{t-1}^{*}
\end{array}\right]+\left[\begin{array}{l}
\mu_{y t} \\
\mu_{\pi t}
\end{array}\right]
$$

By writing (2) in error correction form, we get:

$$
\begin{aligned}
& \begin{array}{l}
x_{i t}-x_{i, t-1}+x_{i, t-1} \\
=\Phi_{1} x_{i, t-1}+\Lambda_{i 0} x_{i, t}^{*}-\Lambda_{i 0} x_{i, t-1}^{*}+\Lambda_{i 0} x_{i, t-1}^{*}+\Lambda_{i 1} x_{i, t-1}^{*} \\
\quad+\mu_{i t}
\end{array} \\
& \begin{array}{l}
\Delta x_{i t}=-\left(I-\Phi_{i}\right) x_{i, t-1}+\left(\Lambda_{i 0}+\Lambda_{i 1}\right) x_{i, t-1}^{*}+\Lambda_{i 0} \Delta x_{i t}^{*}+\mu_{i t} \\
\Delta x_{i t}=\alpha_{i}\left(\beta_{i x}^{\prime} x_{i, t-1}+\beta_{i x^{*}}^{\prime} x_{i, t-1}^{*}\right)+\Lambda_{i 0} \Delta x_{i t}^{*}+\mu_{i t}
\end{array}
\end{aligned}
$$

$\beta_{i}=\left(\beta_{i x^{\prime}}^{\prime}, \beta_{i x^{*}}^{\prime}\right)^{\prime}$ and other parameters are estimated by determining the rank of $\alpha \beta_{i}^{\prime}$ (using the trace statistic or maximum eigenvalue) and $\beta_{i}^{\prime}$. Later, $\beta_{i}^{\prime}$ is estimated by imposing suitable restrictions on the elements of $\beta_{i}^{*}$. These restrictions can be exact or overidentifying. Finally, conditional on $\beta_{i}^{*}$, by (3), the remaining parameters can be consistently estimated using ordinary least squares (OLS).

$$
\Delta x_{i t}=\alpha_{i} E C M_{i, t-1}+\Lambda_{i 0} \Delta x_{i t}^{*}+\mu_{i t}
$$

where $E C M_{i, t-1}=\beta_{i x}^{\prime} x_{i, t-1}+\beta_{i x^{*}}^{\prime} x_{i, t-1}^{*}$ is the vector of long-run cointegrating relationships.

$E C M_{i, t-1}$ are error correction terms that correspond to the $r_{i}$ cointegrating relations of VECMX*. From VECMX ${ }^{*}$, we intend to recover and interpret the number of cointegrating relations, $r_{i}$, the speed of adjustment coefficients, $\alpha_{i}$, and the cointegrating vector, $\beta_{i}$, separately. For instance, if for Pakistan's economy, we consider only the core endogenous variables (output and inflation) and their counterpart foreign-specific 
variables, and assuming $(1,1)$ lags specification, the estimation equation for output, $y$, would yield:

$\Delta y_{t}=\eta_{11} y_{t-1}+\eta_{12} \pi_{t-1}+\eta_{13} y_{t-1}^{*}+\eta_{14} \pi_{t-1}^{*}+\lambda_{11} \Delta y_{t}^{*}+\lambda_{12} \Delta \pi_{t}^{*}+\mu_{y t}$

Finally, (4) presents an estimation structure for the output equation in the presence of foreign-specific variables. The first two elements of the right-hand side of (4) are domestic variables in levels. The next two are foreign-specific variables in levels and the last two elements represent foreign-specific variables in differences. With this, after constructing our foreign-specific (starred) variables, conditional on Pakistan's major trading partner countries, we are now positioned to estimate a Pakistan-specific VECMX model. Our model features domestic (= endogenous) variables and weighted cross-sectional averages of foreign variables augmented by weakly exogenous I (1) variables.

We estimate two models, namely: the augmented model (VECMX*A) and reduced-form model (VECMX*-B). The endogenous variables for VECMX $X^{*}-\mathrm{B}$ are real GDP and inflation, whereas VECMX*-A is augmented by a domestic variable, trade openness, $\mathrm{opn}_{t}$, and a global variable, world oil prices, poil $t$. These models are specified by following the choice of lags order according to the Akaike information criterion and estimated in VEC form based on reduced-rank regression.

\subsection{Weak Exogeneity}

The verification of the weak exogeneity of $x_{i t}^{*}$ with respect to $x_{i t}$ is required to rule out the possibility of long-run feedback from $x_{i t}$ to $x_{i t}^{*}$. One of the prerequisites of our empirical estimation is that the weak exogeneity of country-specific foreign variables $\left(x_{i t}^{*}\right)$ be satisfied in terms of the long-run parameters of the conditional model (di Mauro \& Smith, 2013). Following Johansen (1992), the formal test for weak exogeneity requires an assessment of the joint significance of estimated error correction terms in auxiliary equations for all foreign-specific variables $\left(x_{i t}^{*}\right)$ and global variables.

The weak exogeneity assumption is tested by regressing (5) for each $l$ th component of $x_{i t}^{*}$. This is an F-test of the joint hypothesis that $\delta_{i j, l}=0, j=$ $1,2, \ldots \ldots, r_{i}$ in (5). The lag orders $s_{i}$ and $n_{i}$ are taken as $p_{i}=1$ and $q_{i}=1$. This is the lag order that corresponds to our VECMX* model.

$$
\begin{aligned}
& \Delta x_{i t, l}^{*}= \alpha_{i, l}+\sum_{j=1}^{r_{i}} \delta_{i j, l} E C M_{i j, t-1}+\sum_{k=1}^{s_{i}} \phi_{i k, l}^{\prime} \Delta x_{i, t-k}+\sum_{m=1}^{n_{i}} \psi_{i m, l}^{\prime} \Delta \tilde{x}_{i, t-m}^{*}+ \\
& \eta_{i t, l}
\end{aligned}
$$


where $E C M_{i j, t-1}, j=1,2, \ldots \ldots r_{i}$ are the estimated error correction terms with respect to $r_{i}$ cointegrating relationships for Pakistan (the $i$ th economy) and $\Delta \tilde{x}_{i t}^{*}=\left(\Delta x_{i t}^{\prime *}, \Delta p o i l_{t}^{d}\right)^{\prime}$.

Our results $\left(0.356,0.55\right.$ and 1.98 for $y_{t}^{*}, \pi_{t}^{*}$ and poil $l_{t}^{d}$ with respect to the F-critical value of 2.61) demonstrate that the null hypothesis underlying assumption cannot be rejected at the 5 percent level of significance. This means that the weak exogeneity assumption is satisfied for the key foreignspecific and global variables, and we can safely assume the weak-exogenous property of $y_{t}^{*}, \pi_{t}^{*}$ and poil $l_{t}^{d}$ for the long-run parameters. We can conclude that $y_{t}^{*}, \pi_{t}^{*}$ and poil $l_{t}^{d}$ do not respond to disequilibrium errors but can safely react to the lagged changes.

\section{Data, Variables and Descriptive Statistics}

The annual time-series data, covering the period 1972-2014 and 18 trading partners of Pakistan, is taken from the World Bank's World Development Indicators, the IMF's International Financial Statistics and Direction of Trade Statistics, the Penn World Table 8.1, the OECD database and individual country sources. The average trade flows computed over 2010-12 are used to construct trade weights for all Pakistan's trading partners. Based on these weights, 18 major economies that account for more than 80 percent of Pakistan's international trade are selected to construct the foreign-specific variables.

Given the discussion in Sections 2 and 3, for the specification of our VECMX* model, we include the log of real GDP $\left(y_{i t}\right)$, deflated by $\pi_{i t}$, and the semi-log transformed CPI inflation $\left(\pi_{i t}\right)$ as our key variables. In addition, we include trade openness, measured as the log of the sum of exports and imports as a percentage of GDP $\left(o p n_{i t}\right)$. In accordance with Khan and Senhadji (2001), the semi-log transformation of $\pi_{i t}$ is performed as:

$$
\tilde{\pi}_{i t}=\pi_{i t}-1 \text { if } \pi_{i t} \leq 1 \%
$$

and

$$
\tilde{\pi}_{i t}=\ln \left(\pi_{i t}\right) \text { if } \pi_{i t} \geq 1 \%
$$

The key domestic variables $\left(y_{t}, \pi_{t}, o p n_{t}\right)$ are related to two key foreign-specific variables $\left(y_{t}^{*}, \pi_{t}^{*}\right)$ and a global variable $\left(\right.$ poil $\left.l_{t}^{d}\right)$. World oil prices are included as a global variable. The Appendix describes the data as well as the sources and construction of the foreign-specific variables. Figures 
1 and 2 describe the link matrices of the key variables in relation to the corresponding foreign-specific and global variables.

Figure 1: Pakistan's link matrix: Domestic output and foreign-specific output

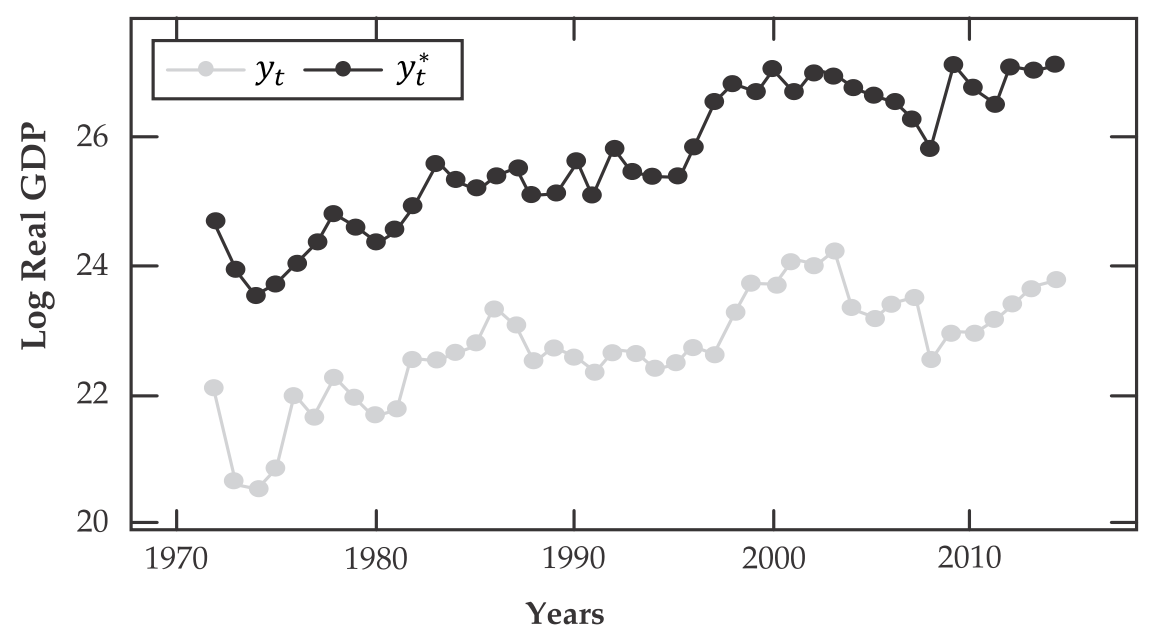

Source: Authors' calculations.

Except for some years, we observe a close relationship between the domestic and foreign-specific variables of Pakistan. To conserve space, we briefly show that a simple relationship between the domestic and foreignspecific key variables (Figures 1 and 2) does exist, barring a few years. Figure 2 demonstrates that the series of domestic inflation and oil prices do not appear to be cointegrated with each other. This shows that, in Pakistan, the relationship between inflation and oil prices is different from that of the rest of the world. ${ }^{9}$ This calls for an in-depth econometric analysis of the inflationoutput dynamics in Pakistan by including foreign-specific and global variables. Nevertheless, we can argue that, if the trends in both types of variables become too different, spillover effects and cross-country interdependencies bring them back toward each other. This happens because of possible integration and trade links between Pakistan and its partner economies.

\footnotetext{
${ }^{9}$ An inverse raw relationship between domestic inflation and oil prices is found for 23 (out of 43) years.
} 
Figure 2: Pakistan's link matrix: Domestic and foreign-specificinflation and world oil prices

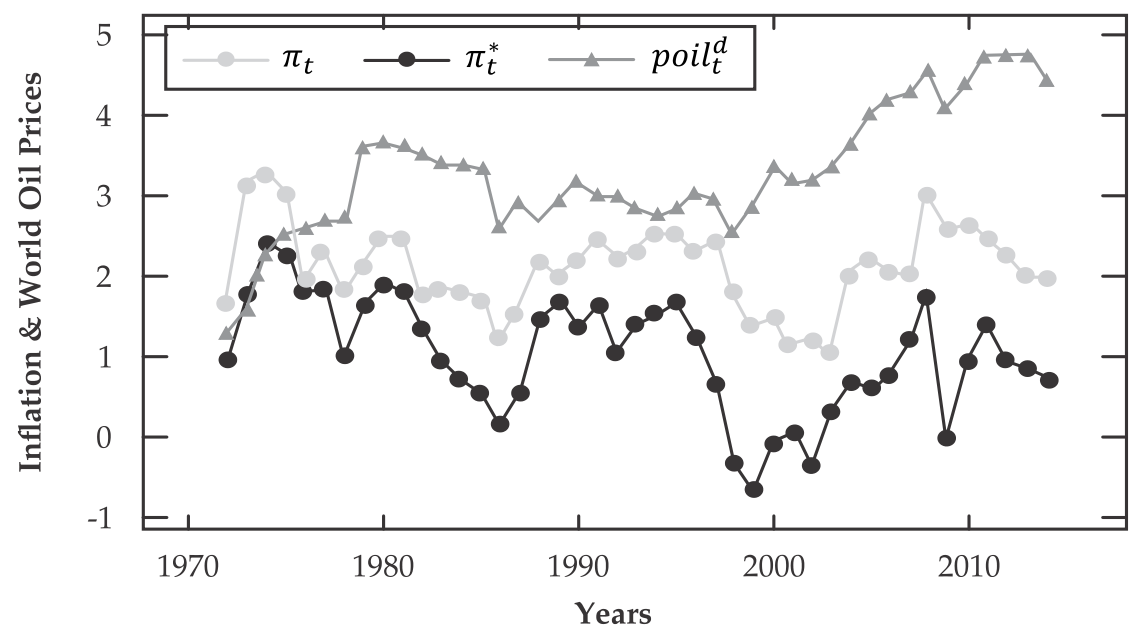

Source: Authors' calculations.

Table 1 reports the summary statistics of the dataset for variables in levels and first differences, after the construction of foreign-specific variables. The foreign-specific variables are constructed as the weighted averages of Pakistan's 18 trading partner countries' data on output and inflation. The standard deviations of variables in levels show that the foreign-specific variables are relatively more dispersed than the domestic variables. We also observe that the averages of the domestic and foreign variables differ. This happens due to differing trade structures and volumes between Pakistan and its partner economies.

Table 1: Descriptive statistics

\begin{tabular}{lllllllllll}
\hline & \multicolumn{3}{c}{ Variables in levels } & \multicolumn{4}{c}{ Variables in first differences } \\
\hline & Mean & SD & Min & Max & & Mean & SD & Min & Max \\
\hline$y_{t}$ & 22.719 & 0.853 & 20.555 & 24.205 & $\Delta y_{t}$ & 0.040 & 0.449 & -1.425 & 1.122 \\
$\pi_{t}$ & 2.115 & 0.522 & 1.070 & 3.283 & $\Delta \pi_{t}$ & 0.008 & 0.451 & -1.072 & 1.493 \\
opn & 5.579 & 0.184 & 5.140 & 5.902 & $\Delta o p n_{t}$ & 0.003 & 0.153 & -0.277 & 0.354 \\
$y_{t}^{*}$ & 25.681 & 1.049 & 23.530 & 27.119 & $\Delta y_{t}^{*}$ & 0.057 & 0.405 & -0.761 & 1.334 \\
$\pi_{t}^{*}$ & 1.036 & 0.716 & -0.610 & 2.395 & $\Delta \pi_{t}^{*}$ & -0.006 & 0.542 & -1.739 & 0.983 \\
poil $_{t}^{d}$ & 3.274 & 0.796 & 1.284 & 4.724 & $\Delta p o i l_{t}^{d}$ & 0.075 & 0.280 & -0.658 & 0.864 \\
\hline
\end{tabular}

Note: The summary statistics show that, although there is not a big difference in the ranges of both types of variables, the foreign-specific variables have greater variation than their counterpart domestic variables. The average domestic inflation is almost double the average foreign-specific inflation in both panels.

Source: Authors' calculations. 


\section{Results and Discussion}

\subsection{Lag Selection, Unit Root Tests and Johansen Cointegration}

Lag selection and cointegrating relations are specified to test for the order of Pakistan-specific cointegrating VECMs. The results of the lag selection, unit root testing and the order of cointegrating relations are reported in Tables 2, 3 and 4, respectively. We start by testing for the suitable lag length for our full variable VECMX*-A using the unrestricted VAR model option. In this respect, the series of domestic variables (output, inflation and trade openness), foreign-specific variables (output and inflation) and global variable (oil prices) are tested for stationarity to identify their integration order and their transformation to a stationary series.

The results of the Dicky-Fuller unit root tests for all selected variables with and without the time trend for both time series in levels and their first differences are reported in Table 2. The Schwarz criterion (SBIC) suggests a VAR(1), the FPE suggests a VAR(2), and the LR and Akaike information criterion (AIC) suggest a VAR (4). However, with respect to the GVAR model when constructing foreign-specific variables, the AIC suggests using a $\operatorname{VAR}(1,1)$ specification. In this empirical setting, we have a relatively small sample of annual frequency data. Hence, we choose to analyze the VECMX ${ }^{*}$-A using the VAR(1) process as suggested by the SBIC and HQIC. For the VECMX $X^{*}$, we follow the lag selection of VAR(2) as suggested by the FPE, AIC and HQIC lag length criteria. Cointegration requires the set of variables to be integrated of the same order.

Table 2: Lag selection for VECMX*s

\begin{tabular}{|c|c|c|c|c|c|c|c|c|}
\hline Lag & LL & LR & df & $\mathrm{p}$ & FPE & AIC & HQIC & SBIC \\
\hline \multicolumn{9}{|c|}{$\mathrm{VECMX}^{*}-\mathrm{A}$} \\
\hline 0 & -69.06 & & 36 & & $1.90 \mathrm{E}-06$ & 3.849 & 3.941 & 4.105 \\
\hline 1 & 131.874 & 401.87 & 36 & 0.000 & 4.10E-10 & -4.609 & $-3.966^{*}$ & $-2.817^{*}$ \\
\hline 2 & 170.802 & 77.855 & 36 & 0.000 & $4.0 \mathrm{e}-10^{*}$ & -4.759 & -3.565 & -1.432 \\
\hline 3 & 204.885 & 68.165 & 36 & 0.001 & $6.60 \mathrm{E}-10$ & -4.661 & -2.916 & 0.202 \\
\hline 4 & 243.66 & $77.362^{*}$ & 36 & 0.000 & $1.40 \mathrm{E}-09$ & $-4.798^{*}$ & -2.503 & 1.600 \\
\hline \multicolumn{9}{|c|}{ VECMX*-B } \\
\hline 0 & -65.245 & & 16 & & 0.0004 & 3.551 & 3.612 & 3.721 \\
\hline 1 & 89.826 & 310.130 & 16 & 0.000 & $3.3 e-07$ & -3.581 & -3.275 & $-2.728^{*}$ \\
\hline 2 & 111.715 & 43.779 & 16 & 0.000 & $2.5 \mathrm{e}-07^{*}$ & $-3.883^{*}$ & $-3.332^{*}$ & -2.347 \\
\hline 3 & 121.328 & 19.225 & 16 & 0.001 & $3.7 e-07$ & -3.555 & -2.759 & -1.337 \\
\hline 4 & 134.610 & $26.564^{*}$ & 16 & 0.000 & $5.0 \mathrm{e}-07$ & -3.416 & -2.375 & -0.515 \\
\hline
\end{tabular}

Notes: The number of lags is determined using the SBIC and HQIC for the VECMX*-A and the AIC, FPE and HQIC for the VECMX*-B. * ${ }^{* *}$ and ${ }^{* * *}$ signify that the unit root test hypothesis is rejected at $10 \%, 5 \%$ and $1 \%$, respectively.

Source: Authors' calculations. 
Table 3: Results of unit root test

\begin{tabular}{|c|c|c|c|c|c|}
\hline \multirow[b]{2}{*}{ Variable } & \multicolumn{2}{|c|}{ Level } & \multicolumn{2}{|c|}{ First difference } & \multirow[b]{2}{*}{ Order } \\
\hline & No trend & Trend & No trend & Trend & \\
\hline \multicolumn{6}{|c|}{ VECMX*-A (lags = 1) } \\
\hline$y_{t}$ & -2.29 & -2.89 & $-5.5^{* * *}$ & $-5.56^{* * *}$ & $\mathrm{I}(1)$ \\
\hline$\pi_{t}$ & $-3.10^{* *}$ & -3.02 & $-5.44^{* * *}$ & $-5.45^{* * *}$ & $\mathrm{I}(1)$ \\
\hline$o p n_{t}$ & $-2.79^{*}$ & -2.65 & $-5.67^{* * *}$ & $-5.61^{* * *}$ & $\mathrm{I}(1)$ \\
\hline$y_{t}^{*}$ & -1.21 & -3.008 & $-6.03^{* * *}$ & $-6.249^{* * *}$ & $\mathrm{I}(1)$ \\
\hline$\pi_{t}^{*}$ & -2.59 & -3.06 & $-5.69 * * *$ & $-5.65^{* * *}$ & $\mathrm{I}(1)$ \\
\hline$o p n_{t}^{*}$ & -1.56 & -2.84 & $-5.57^{* * *}$ & $-5.6^{* * *}$ & $\mathrm{I}(1)$ \\
\hline poil $_{t}^{d}$ & -2.034 & -2.37 & $-4.76^{* * *}$ & $-4.69^{* * *}$ & $\mathrm{I}(1)$ \\
\hline \multicolumn{6}{|c|}{ VECMX*-B (lags = 2) } \\
\hline$y_{t}$ & -2.60 & -3.056 & $-4.71^{* * *}$ & $-4.82^{* * *}$ & $\mathrm{I}(1)$ \\
\hline$\pi_{t}$ & $-3.26^{* *}$ & -3.13 & $-4.65^{* * *}$ & $-4.69^{* * *}$ & $\mathrm{I}(1)$ \\
\hline$y_{t}^{*}$ & -1.46 & -2.52 & $-4.58^{* * *}$ & $-4.62^{* * *}$ & $\mathrm{I}(1)$ \\
\hline$\pi_{t}^{*}$ & -2.44 & -2.54 & $-4.25^{* * *}$ & $-4.27^{* * *}$ & $\mathrm{I}(1)$ \\
\hline
\end{tabular}

Note: The results give the order of integration of the VECMX*s and show that an I(1) process characterizes all the variables best. We apply the same unit root tests to the first differences of the domestic and foreign-specific variables; in all cases, we reject the null hypothesis of unit root. In both models, the number of lags is determined using the SBIC and HQIC in VECMX*-A and the AIC, FPE and HQIC in VECMX*-B. *, ** and ${ }^{* * *}$ mean that the unit root test hypothesis is rejected at 10,5 and $1 \%$, respectively.

Source: Authors' calculations.

Considering the stationarity tests for the domestic and foreignspecific variables, the unit root tests reported in Table 3 show that all the selected variables (except inflation with no trend) are nonstationary in levels. However, all are stationary at the one percent significance level in first differences. The conventional unit root test statistics based on the augmented Dicky-Fuller method do not reject the null hypothesis of the presence of a unit root in all variables in both models in levels at the conventional 1, 5 or 10 percent levels. Therefore, the OLS estimates of these variables in level form may give misleading estimates of standard errors.

The standard literature on cointegration suggests that two or more series are cointegrated if they have a long-term equilibrium relationship. In the short run, they may deviate from each other temporarily. This means that one cointegrated series cannot arbitrarily drift apart from another. The existing cointegration between the domestic and foreign-specific variables shows that the series in question have a common trend. Therefore, regressing one series on the other will not generate spurious estimates. 
The most commonly used test to examine cointegration is the maximum likelihood (ML) test proposed by Johansen (1988). The Johansen trace statistic at a 95 percent critical level is used to determine the ranks of both cointegrating vectors VECMX*-A and VECMX*-B. The Johansen (1988) ML procedure in STATA is used to test for the existence of cointegrating relationships. To capture the long-term links between the domestic and foreign-specific variables, we first perform the Johansen trace cointegration test. The test is based on the null of no cointegration between output, inflation and the other series of interest.

Table 4: Johansen test for cointegration

\begin{tabular}{|c|c|c|c|c|c|c|c|}
\hline (1) & (2) & (3) & (4) & (5) & (6) & (7) & (8) \\
\hline$r$ & Eigenval. & $\begin{array}{c}\text { Trace } \\
\text { stat. }\end{array}$ & $\begin{array}{c}5 \% \text { Cr. } \\
\text { val. }\end{array}$ & $r$ & Eigenval. & $\begin{array}{c}\text { Trace } \\
\text { stat. }\end{array}$ & $\begin{array}{c}5 \% \text { Cr. } \\
\text { val. }\end{array}$ \\
\hline \multicolumn{2}{|c|}{ VECMX ${ }^{*}$-A $($ lags $=1)$} & \multicolumn{6}{|c|}{ VECMX*-B (lags = 2) } \\
\hline$r_{0}=0$ & -- & 128.617 & 114.90 & $r_{0}=0$ & -- & 69.3955 & 47.21 \\
\hline$r_{0} \leq 1$ & 0.627 & $87.199 *$ & 87.31 & $r_{0} \leq 1$ & 0.5998 & 31.8478 & 29.68 \\
\hline$r_{0} \leq 2$ & 0.448 & 62.213 & 62.99 & $r_{0} \leq 2$ & 0.34069 & $14.7691^{*}$ & 15.41 \\
\hline$r_{0} \leq 3$ & 0.439 & 37.954 & 42.44 & $r_{0} \leq 3$ & 0.21266 & 4.9662 & 3.76 \\
\hline$r_{0} \leq 4$ & 0.334 & 20.889 & 25.32 & $r_{0} \leq 4$ & 0.11408 & -- & -- \\
\hline
\end{tabular}

Note: Table 4 presents the results of the determination of cointegrating relations in the VECMX*s. The number of lags is determined using the SBIC and HQIC in VECMX*-A and the AIC, FPE and HQIC in VECMX*-B. The maximum eigenvalue, trace statistics and respective critical values at the $5 \%$ significance level are reported in columns 2, 3 and 4 and 6, 7 and 8 for VECMX*-A and VECMX*-B, respectively.

Source: Authors' calculations.

Since we observe that the set of variables is found to have one cointegrating vector in VECMX ${ }^{*}-\mathrm{A}$ and two cointegrating vectors in VECMX $X^{*} B$, vector error correction modeling is a suitable estimation technique, given its ability to adjust to both short-run and long-run changes in variables and deviations from equilibrium. Table 4 reports the results of the maximum eigenvalue, trace statistics and respective critical values at a 5 percent significance level. In the case of $k=1$ (VECMX $\left.{ }^{*}-\mathrm{A}\right)$, the trace test indicates that there is no more than one cointegrating relationship; in the case of $k=2\left(V^{2} C M X^{*}-\mathrm{B}\right)$, there are no more than two cointegrating relationships. 


\subsection{Inflation-Output Dynamics in the Presence of Foreign-Specific and Global Variables}

\subsubsection{Adjustment Parameters, $\hat{\alpha}$}

In this section, we discuss our results. To better guide the reader, we present only those parameter estimates that are directly related to the principal objective of this article. A crucial step in the estimation of VECMX ${ }^{*}$ models is to describe the dynamic adjustment of the key variables to the long-run equilibrium. It is possible to evaluate, with these estimates, the adjustment speed toward equilibrium or the short-term deviations from equilibrium. The adjustment parameters measure the speed of adjustment of variables to their equilibrium level. All selected variables are considered endogenous, in the STATA environment, to establish the joint effect of variables in VECMX*-A and VECMX ${ }^{*}-\mathrm{B}$, and to establish their long-run association with one another.

By applying one cointegrating equation for VECMX*-A and two cointegrating equations for $\mathrm{VECMX}{ }^{*}-\mathrm{B}$, we estimate a system of six equations using OLS. The existing long-run cointegrating relationship between domestic output and inflation, and between domestic and foreign variables suggests that the impact of these variables on the domestic variables is not limited to the short run. However, to conserve space, we report only the long-run estimates. Statistical significance and the size of the coefficient of the error correction term are used to measure the propensity of each variable to return to equilibrium: the significant coefficients of $\Delta y_{t}$ and $\Delta \pi_{t}$ imply that deviations from equilibrium can be corrected. This suggests that any movements in foreign-specific and global variables can be used to predict the movement of inflation and output. The results show that our model fits the data well in explaining the long-run relationship between inflation and output in the presence of both foreignspecific and global variables.

Table 5 reports the parameters of the model's adjustment matrix. The coefficients of the key variables, $\Delta y_{t}, \Delta \pi_{t}$ and $\Delta$ poil $_{t}^{d}$, are statistically significant, have the correct signs and imply moderate adjustment toward equilibrium. It is worth noting that the coefficients of the domestic output and inflation variables have the expected negative and positive signs respectively and are significant. 
Table 5: Error correction models: Adjustment parameters

\begin{tabular}{|c|c|c|c|c|c|c|c|}
\hline & & $\Delta y_{t}$ & $\Delta \pi_{t}$ & $\Delta o p n_{t}$ & $\Delta y_{t}^{*}$ & $\Delta \pi_{t}^{*}$ & $\Delta p o i l_{t}^{d}$ \\
\hline \multicolumn{8}{|c|}{ VECMX*-A } \\
\hline$\alpha$ & $c e 1$ & $\begin{array}{l}-0.209^{*} \\
(0.117)\end{array}$ & $\begin{array}{l}0.224^{*} \\
(0.117)\end{array}$ & $\begin{array}{l}-0.010 \\
(0.414)\end{array}$ & $\begin{array}{l}0.133 \\
(0.108)\end{array}$ & $\begin{array}{l}-0.029 \\
(0.147)\end{array}$ & $\begin{array}{l}-0.124^{*} \\
(0.073)\end{array}$ \\
\hline \multicolumn{8}{|c|}{ VECMX ${ }^{*}-B$} \\
\hline$\alpha$ & $c e 1$ & $\begin{array}{l}-0.23 \\
(0.49)\end{array}$ & $\begin{array}{l}-0.08 \\
(0.257)\end{array}$ & -- & $\begin{array}{l}1.00^{* *} \\
(0.448)\end{array}$ & $\begin{array}{l}-0.21 \\
(0.648)\end{array}$ & -- \\
\hline$\alpha$ & $c e 2$ & $\begin{array}{l}0.15 \\
(0.51)\end{array}$ & $\begin{array}{l}0.19 \\
(0.486)\end{array}$ & -- & $\begin{array}{l}0.54 \\
(0.467)\end{array}$ & $\begin{array}{l}0.49 \\
(0.676)\end{array}$ & -- \\
\hline
\end{tabular}

Notes: Standard errors are reported in parentheses. ${ }^{* *}$ and * signify $5 \%$ and $10 \%$ levels, respectively. The table shows that the cointegrating analysis of foreign-specific and a global variable along with key domestic variables fully explain inflation-output tradeoff dynamics in Pakistan. The VECMX*-A results indicate that a long-run equilibrium relationship exists between inflation and output. The adjustment parameters of $c e 1$ in VECMX*-A have the correct signs with a moderate magnitude. The VECMX*-A estimates are therefore consistent with our hypothesis that international linkages, trade spillovers and worldwide trends drive inflation-output tradeoff dynamics in Pakistan. [Upper panel] AIC $=-3.929, \mathrm{HQIC}=$ -3.929 and SBIC $=-3.226$. [Lower panel] AIC $=-3.38, \mathrm{HQIC}=-2.90$ and $\mathrm{SBIC}=-2.047$.

Source: Authors' calculations.

\subsubsection{Constraints on Parameters in $\widehat{\beta}(E C M)$}

Since our task is to determine whether the foreign-specific and global variables have any impact on key domestic variables, we also test each of the variables individually for significance. To observe the transmission channels by which foreign-specific and global variables affect domestic output and inflation, we complement our analysis by estimating a multivariate model (VECMX $\left.{ }^{*}-\mathrm{A}\right)$ intended to analyze and capture the significance of crosscountry linkages and global trends.

To test whether the long-run elasticities from $\hat{\beta}$ are valid and significant, we estimate an alternative bivariate model, VECMX ${ }^{*}$-B, (without foreign variables) and, using the LR test, find that $y_{t}$ contributes significantly to the cointegrating relationship. The result (that is $\operatorname{LR} \chi^{2}(3)=122.97$, Prob $>\chi^{2}=0.000$ ) demonstrates that our model performed well in terms of significance. By normalizing $\hat{\beta}$ with respect to the coefficients of $y_{t}$ and $\pi_{t}$, the existing cointegrating vectors of VECMX*-A and VECMX ${ }^{*}$-B yield the relationships presented in Table 6, columns (2) and (3).

Considering our core variable of output (GDP), its long-run relationship in both models appears to be negative with respect to domestic inflation $\left(\pi_{t}\right)$ and foreign GDP $\left(y_{t}^{*}\right)$, though the latter is not significant. This 
is in line with our conjecture and the earlier literature on inflation-output dynamics. In VECMX ${ }^{*}$ A, the coefficient of $\pi_{t}$ shows that, in the presence of trade spillovers, a one-unit increase in inflation lowers output by 0.48 percentage points. The magnitude of the effect of $\pi_{t}$ on $y_{t}$ is much higher than that estimated without the interdependencies of the partner economies. For instance, Ayyoub and Woerz (2016) recently estimate that, without taking into account the trade spillovers among developing economies, a 10 percent increase in inflation reduces GDP growth by just $0.12-0.20$ percentage points.

Table 6: Vector error correction models (VECMX*)

\begin{tabular}{lccc}
\hline & VECMX*-A & \multicolumn{2}{c}{ VECMX $^{*}$-B } \\
\cline { 2 - 4 } Variable & $\boldsymbol{y}_{\boldsymbol{t}}$ & $\boldsymbol{y}_{\boldsymbol{t}}$ & $\boldsymbol{\pi}_{\boldsymbol{t}}$ \\
\hline$\pi_{t}$ & $-0.48^{*}$ & -- & - \\
& $(0.264)$ & & -- \\
opn $_{t}$ & $0.97^{*}$ & -- & $-0.17^{* * *}$ \\
& $(0.540)$ & & $(0.065)$ \\
$y_{t}^{*}$ & -1.11 & $-0.55^{* * *}$ & $-0.87^{* * *}$ \\
& $(0.324)$ & $(0.083)$ & $(0.093)$ \\
$\pi_{t}^{*}$ & -0.23 & $0.53^{* * *}$ & -- \\
& $(0.49)$ & $(0.118)$ & \\
poil $_{t}^{d}$ & $0.37^{* *}$ & -- & \\
\hline
\end{tabular}

Note: Table 6 presents long-run (ECM) estimates with an already defined order of integration for VECMX*-A and VECMX*-B. Standard errors are reported in parentheses. We conclude that a long-run equilibrium relationship exists in VECMX*-A and VECMV*B. These estimates explain that international linkages and trade spillovers drive the longrun inflation-output tradeoff dynamics. However, VECMX*-A is our preferred model as it is well determined in the presence of domestic, foreign-specific and global variables. ${ }^{*}, * *$ and ${ }^{* * *}$ signify $10 \%, 5 \%$ and $1 \%$ levels, respectively.

Source: Authors' calculations.

The impact of $\pi_{t}^{*}$ on $y_{t}$ is statistically insignificant in VECMX ${ }^{*}-\mathrm{A}$. However, this effect is not only significant in VEMX*-B but also has a large estimated magnitude. The implied elasticity between $\pi_{t}^{*}$ and $y_{t}$ shows that a 1 percent increase in foreign-specific inflation increases the GDP of Pakistan by 0.53 percentage points. The economic argument for this effect is that inflation in Pakistan's trading partners results in higher exports and revenues for Pakistan, which in turn boosts the domestic GDP. Another significant result in VECMX ${ }^{*}$-A is the positive impact of $o p n_{t}$ on GDP for Pakistan. Since opn is the sum of exports and imports, we can argue that this variable is the channel through which the trade spillovers of the foreign variables exert their effect on Pakistan's inflation-output dynamics. The 
economic meaning of the coefficient of opn reveals that the direct relationship between trade openness and GDP is approximately equal to unity for Pakistan.

The relationships between $\pi_{t}$ and $\pi_{t}^{*}$, and $\pi_{t}$ and $y_{t}^{*}$ are also negative and significant according to the last column of Table 6 . Therefore, we can conclude that domestic inflation not only causes domestic output to decrease (by 0.48 percent as explained above), but it is also affected by the output of Pakistan's partner economies. The magnitude of this impact elasticity is 0.174 . We can interpret the result as a one percentage point increase in foreign output tends to reduce domestic inflation by 0.174 points.

The coefficient of poil $l_{t}^{d}$ is 0.37 . This means that an increase in oil prices of one unit causes output to increase by 0.37 percentage points. Since Pakistan is a net importer of oil products, at face value, the implied elasticity provides the opposite result relative to theory. However, if we consider the indirect effects framework of Abeysinghe (2001), we can argue that the effects of an increase in poil work through Pakistan's trading partners. Pakistan's major export destinations are all oil-exporting economies (for example, Saudi Arabia and the UAE): with an increase in oil prices, Pakistan reaps the benefits from its oil-exporting partner countries in terms of increased export revenue and increased remittances. Therefore, an increase in poil, in turn, increases the imports of oil-exporting countries from Pakistan. Hence, the net effect on Pakistan depends on its trade (imports and exports) potential.

Although this article is a unique empirical attempt to examine the relationship in question, we compare our results with some earlier studies that consider inflation, output and oil prices as variables in a VECM environment. Our estimates are in sharp contrast to Mallik and Chowdhury (2001) who document a long-run positive relationship between inflation (coefficient $=0.085$ ) and output (coefficient $=0.2627$ ) in Pakistan and three other South Asian economies. A negative long-run inflation-growth relationship is also documented in the cross-sectional panel studies carried out by Barro (1996) and Khan and Senhadji (2001). However, we would stress that they examine the relationship by adopting different empirical settings, econometric techniques and variables. Taking into account the oil price variable, Hartmann and Roestel (2013) find a negative relationship between inflation and output for many Asian economies, although the magnitude of the effect of inflation on output is almost twice the size of the effect found in our results. 
Before concluding this section, we briefly discuss some postestimation significance and specification testing checks to determine the estimated models' stability. Validating the inference of the adjustment parameters $(\alpha)$ generally relies on the stationarity of cointegrating equations over time, and involves conducting several specification tests and stability checks. ${ }^{10}$ In addition, the companion matrix of VECMX ${ }^{*}-\mathrm{A}(K=6 ; r=1)$ and VECMX ${ }^{*}$-B $(K=4 ; r=2)$ have $K-r$ unit eigenvalues. We find that the processes are stable as the moduli of the remaining $r$ eigenvalues are strictly less than 1 . This implies that the models are specified accurately. Next, We test for serial correlation in residuals under the null hypothesis of no autocorrelation at lag order. The results [i.e., $\chi^{2}=22.19(\mathrm{p}=0.965)$ for VECMX $X^{*}-\mathrm{A}, \chi^{2}=16.67(\mathrm{p}=0.41)$ for VECMX ${ }^{*}-\mathrm{B}$ at lag 1 and $\chi^{2}=12.14(\mathrm{p}=$ 0.73 ) for $\mathrm{VECMX}{ }^{*}-\mathrm{B}$ at lag $=2$ ] demonstrate that there is no evidence of serial correlation in the residuals. Thus, we cannot reject the null hypothesis of no correlation at lag order.

Based on the estimated parameters and stability of our preferred model, we find proof for our hypothesis that foreign-country effects matter in the long-run relationship between inflation and output in Pakistan. Given that the estimated results of domestic key variables are in accordance with the literature, we find evidence that supports the idea that an inflationoutput tradeoff exists in the presence of common swings across trading partners. Moreover, when taking into account foreign trade spillovers, the magnitude of the effect of inflation on output becomes more pronounced.

\section{Concluding Remarks}

In this article, we analyze time-series data from Pakistan and 18 of its major trading partners, which account for more than 80 percent of its international trade over the period 1972-2014. We empirically examine the connection between the inflation-output tradeoff and common global swings and cross-country trade interactions for Pakistan. For this purpose, we use the GVAR method and construct foreign-specific variables for Pakistan as weighted averages of the foreign variables of 18 trading partners. After ensuring that the foreign-specific variables meet the assumption of weak exogeneity, they are systematically included as endogenous variables in the Pakistan-specific vector error correction model. By doing so, we incorporate international linkages along with domestic inflation-output variables, and evaluate the patterns of co-movement in a multi-country framework.

\footnotetext{
${ }^{10}$ The graphs of the cointegrating equations and model stability checks are not given here, but the results are available from the authors.
} 
The cointegration analysis results provide evidence that economic developments in trading partners matter significantly when explaining inflation-output dynamics in Pakistan, and that a stable, well-determined long-run equilibrium relationship exists between key variables. More specifically, a 1 percent increase in domestic inflation and openness cause domestic output to fall by 0.48 and 0.97 basis points, respectively. A 1 percent increase in world oil prices is followed by an increase in domestic output of 0.37 percentage points.

Our results indicate that, since Pakistan is increasingly integrated with key global players through trade, worldwide developments play a crucial role in explaining domestic output and inflation. Based on this outcome, an important policy implication is that the State Bank of Pakistan should also consider global developments, specifically among its trading partner economies. Our findings contribute to the literature on the existing debate over whether economic growth in Pakistan is driven mainly by internal factors or whether it is an economy impacted by global developments. In accordance with Ayyoub (2018), our study supports the view that economic growth in Pakistan is driven not only by internal factors, but also depends on international linkages, global trends and thirdcountry effects.

However, as the study does not consider the ongoing global debate about the efficacy of counter-cyclical demand management policies (Keynesian) in warding off the effects of economic recession, its scope is limited. Moreover, as an analysis based on quarterly data may provide more useful insights, its limited availability in Pakistan restricts the scope of this study. To that effect, including more endogenous financial variables (for instance, the interest rate) could improve the dynamic properties of our estimated model. In addition, a full-fledged GVAR model assessment of Pakistan that includes more global trading players would help examine the impact elasticities of foreign variables, while generalized impulse response functions would illustrate more dynamic information on all Pakistan's trading partners. This is a potential agenda for future research. 


\section{References}

Abel, A., \& Bernanke, B. (2001). Macroeconomics. New York: Addison Willey Longman.

Abeysinghe, T. (2001). Estimation of direct and indirect impact of oil price on growth. Economics Letters, 73(2), 147-153.

Ayyoub, M. (2018, September). International linkages of inflation-output dynamics: Fresh GVAR evidence from Pakistan and its trading partners. Paper presented at the Annual Meeting of the Slovak Economic Association, Comenius University in Bratislava.

Ayyoub, M., \& Woerz, J. (2016). Long run inflation-growth nexus in developing economies: Old wine in a new bottle. Journal of Business and Economics, 8(2), 114-127.

Barro, R. J. (1996). Inflation and growth. Federal Reserve Bank of St. Louis Review, 78(3), 153-169.

Barro, R. J., \& Sala-i-Martin, X. (1995). Economic growth. New York: McGraw-Hill.

Blanchard, O. J., \& Riggi, M. (2013). Why are the 2000s so different from the 1970s? A structural interpretation of changes in the macroeconomic effects of oil prices. Journal of the European Economic Association, 11(5), 1032-1052.

Cunado, J., \& de Gracia, F. P. (2005). Oil prices, economic activity and inflation: Evidence for some Asian countries. Quarterly Review of Economics and Finance, 45(1), 65-83.

Dees, S., di Mauro, F., Pesaran, M. H., \& Smith, L. V. (2007). Exploring the international linkages of the euro area: A global VAR analysis. Journal of Applied Econometrics, 22(1), 1-38.

Dees, S., Pesaran, M. H., Smith, L. V., \& Smith, R. P. (2014). Constructing multi-country rational expectations models. Oxford Bulletin of Economics and Statistics, 76(6), 812-840.

Dholakia, R. H. (1990). Extended Phillips curve for the Indian economy. Indian Economic Journal, 38(1), 69-78. 
di Mauro, F., \& Smith, L. V. (2013). The basic GVAR DdPS model. In F. di Mauro and M. H. Pesaran (Eds.), The GVAR handbook: Structure and applications of a macro model of the global economy for policy analysis (pp. 12-32). Oxford: Oxford University Press.

Fuhrer, J. C. (1995). The Phillips curve is alive and well. New England Economic Review, 2, 41-56.

Ghani, E. (1991). Rational expectations and price behavior: A study of India. Journal of Development Economics, 36(2), 295-311.

Gylfason, T. (1999). Exports, inflation and growth. World Development, 27(6), 1031-1057.

Hamilton, J. D. (2016). Oil and the macroeconomy. In S. Durlauf \& L. Blume (Eds.), The new Palgrave dictionary of economics. London: Palgrave Macmillan.

Hartmann, M., \& Roestel, J. (2013). Inflation, output and uncertainty in the era of inflation targeting: A multi-economy view on causal linkages. Journal of International Money and Finance, 37, 98-112.

Hooker, M. A. (2002). Are oil shocks inflationary? Asymmetric and nonlinear specifications versus changes in regime. Journal of Money, Credit and Banking, 34(2), 540-561.

Hussain, S., \& Malik, S. (2011). Inflation and economic growth: Evidence from Pakistan. International Journal of Economics and Finance, 3(5), 262-276.

Johansen, S. (1988). Statistical analysis of cointegration vectors. Journal of Economic Dynamics and Control, 12(2-3), 231-254.

Johansen, S. (1992). Cointegration in partial systems and the efficiency of single-equation analysis. Journal of Econometrics, 52(3), 389-402.

Khan, M. S., \& Senhadji, A. S. (2001). Threshold effects in the relationship between inflation and growth. IMF Staff Papers, 48(1), 1-21.

Lopez-Villavicencio, A., \& Mignon, V. (2011). On the impact of inflation on output growth: Does the level of inflation matter? Journal of Macroeconomics, 33(3), 455-464.

Lucas Jr, R. E. (1976). Econometric policy evaluation: A critique. CarnegieRochester Conference Series on Public Policy, 1, 19-46. 
Mallik, G., \& Chowdhury, A. (2001). Inflation and economic growth: Evidence from four South Asian countries. Asia-Pacific Development Journal, 8(1), 123-135.

Mankiw, N. G., Romer, D., \& Weil, D. N. (1992). A contribution to the empirics of economic growth. Quarterly Journal of Economics, 107(2), 407-437.

Mazumder, S. (2011). The stability of the Phillips curve in India: Does the Lucas critique apply? Journal of Asian Economics, 22(6), 528-539.

Moazam, M., \& Kemal, M. A. (2016). Inflation in Pakistan: Money or oil prices (Working Paper No. 144). Islamabad: Pakistan Institute of Development Economics.

Mubarik, Y. A. (2005). Inflation and growth: An estimate of the threshold level of inflation in Pakistan. SBP Research Bulletin, 1(1), 35-44.

Pesaran, M. H., Schuermann, T., \& Weiner, S. M. (2004). Modeling regional interdependencies using a global error-correcting macroeconometric model. Journal of Business and Economic Statistics, 22(2), 129-162.

Qayyum, A. (2008). Does monetary policy play effective role in controlling inflation in Pakistan (MPRA Paper No. 13080). Retrieved from https://mpra.ub.uni-muenchen.de/13080/

Saleem, N. (2010). Adopting inflation targeting in Pakistan: An empirical analysis. Lahore Journal of Economics, 15(2), 51-76.

Virmani, V. (2004). Estimating output gap for the Indian economy: Comparing results from unobserved-components models and the Hodrick-Prescott filter (Working Paper 04-02). Ahmedabad: Indian Institute of Management Ahmedabad. 
Appendix

Table A1: Pakistan's international trade flows (based on average exports and imports of all commodities in USD: 2010-12)

\begin{tabular}{|c|c|c|c|c|c|}
\hline (1) & (2) & (3) & (4) & (5) & (6) \\
\hline No. & Country & Weight & No. & Country & Weight \\
\hline 1 & China & 0.200 & 2 & France & 0.021 \\
\hline 3 & Germany & 0.040 & 4 & Indonesia & 0.023 \\
\hline 5 & Iran & 0.035 & 6 & Italy & 0.026 \\
\hline 7 & India & 0.045 & 8 & Japan & 0.038 \\
\hline 9 & Kuwait & 0.054 & 10 & Malaysia & 0.048 \\
\hline 11 & South Korea & 0.027 & 12 & Saudi Arabia & 0.111 \\
\hline 13 & Singapore & 0.027 & 14 & Thailand & 0.019 \\
\hline 15 & Turkey & 0.017 & 16 & UAE & 0.135 \\
\hline \multirow[t]{2}{*}{17} & United Kingdom & 0.034 & 18 & USA & 0.097 \\
\hline & & & & & $\operatorname{Sum}(3+6)=1.00$ \\
\hline
\end{tabular}

Note: Columns (2) and (5) indicate Pakistan's partner economies; columns (3) and (6) give their respective trade weights in Pakistan's foreign trade.

Source: Authors' calculations based on data from DOTS (IMF).

\section{Table A2: Variables and data sources}

\begin{tabular}{|c|c|c|}
\hline (1) & ${ }^{(2)}$ & (3) \\
\hline Variable & Definition and unit & Source \\
\hline Real GDP $\left(y_{t}\right)$ & $\begin{array}{l}\text { Log of annual GDP at constant } 2005 \text { national } \\
\text { prices deflated by } \pi_{t}\end{array}$ & PWT \\
\hline CPI inflation $\left(\pi_{t}\right)$ & Semi-log transformed annual rate of CPI inflation & WEO \\
\hline $\begin{array}{l}\text { Trade openness } \\
\left(o p n_{t}\right)\end{array}$ & $\begin{array}{l}\text { Sum of exports and imports as \% of GDP at } 2005 \\
\text { constant prices }\end{array}$ & WDI \\
\hline Oil prices $\left(\right.$ poil $\left._{t}^{d}\right)$ & Log of annual price of oil (in USD) & $\begin{array}{l}\text { GVAR toolbox } \\
\text { (2014) }\end{array}$ \\
\hline Weight $\left(w_{i j}\right)$ & $\begin{array}{l}\text { Bilateral trade flow from Pakistan }(i) \text { to trading } \\
\text { partners }(j) \text {, measured in terms of imports and } \\
\text { exports of goods and services }\end{array}$ & DOTS \\
\hline $\begin{array}{l}\text { Domestic variables } \\
\left(y_{t}, \pi_{t}, \text { op } n_{t}\right)\end{array}$ & Foreign-specific and global variables $\left(y_{t}^{*}, \pi_{t}^{*}\right.$, poil $\left.l_{t}^{d}\right)$ & \\
\hline
\end{tabular}

